\title{
Propostas de Configurações para Transmissão em Micro-ondas do Padrão DVB-T
}

\author{
Settings proposal for DVB-T microwave transmissions
}

Hugo A. D. Almaguer ${ }^{1,2}$ (Dorcid.org/0000-0002-3215-750X

\begin{abstract}
Alisson Heidemann ${ }^{2,3}$ (Dorcid.org/0000-0002-8840-9323
Kayo Barbosa ${ }^{1,4}$ Dorcid.org/0000-0003-0501-0470

${ }^{1}$ Centro de Ciências Tecnológicas, UniversidadeRegional de Blumenau, Santa Catarina, Brasil,

2 Programa de Pós-graduação em Engenharia Elétrica - Mestrado,Universidade Regional de Blumenau, Santa Catarina, Brasil,

${ }^{3}$ Grupo NSC Comunicações, Santa Catarina, Brasil,

${ }^{4} \mathrm{OI} / \mathrm{SA}$, Santa Catarina, Brasil.

E-mail do autor principal: Hugo A. D. Almaguer hugo@furb.br
\end{abstract}

\section{RESUMO}

Este artigo apresenta um estudo sobre enlaces terrestres de micro-ondas para transmissão de sinais de televisão digital, com ênfase na análise das configurações praticadas dos parâmetros da Multiplexação Ortogonal por Divisão de Frequência: código de correção de erro, intervalo de guarda e tipo de modulação. Foram executados testes práticos e simulados, referentes a casos de enlaces na região metropolitana de Porto Alegre/RS, representativos da diversidade de condições topográficas e distâncias que podem ser tipicamente encontradas durante as transmissões convencionais. A análise dos estudos de caso resultou no desenvolvimento de propostas de combinações idôneas dos parâmetros da modulação digital, no intuito de viabilizar enlaces com a robustez e a qualidade adequada para cada situação específica de transmissão.

PALAVRAS-CHAVE: COFDM; Enlaces de micro-ondas; Parâmetros de transmissão de TV digital;

\section{ABSTRACT}

This paper aims contributing to the study of microwave terrestrial links for digital television signals transmission. In order to investigate the effect of the Coded Orthogonal Frequency Division Multiplexparameter setting (forward error correction, guard interval and type of modulation) over the signal behavior, some practical and simulated link tests were carried out at the metropolitan region of Porto Alegre. The analysis of the results has allowed the development of some suitable combinations of these digital modulation parameters to make feasible transmission links with robustness and adequate quality for each specific topographic situation.

KEY-WORDS: COFDM; Microwave links; Parameters of digital TV transmission; 


\section{INTRODUÇÃO}

Com a migração do sistema analógico de televisão para o digital, houve grandes mudanças na área da transmissão de micro-ondas para a distribuição dos sinais de TV. O padrão de transmissão digital usado na maioria dos países é - Digital Video Broadcasting (DVB), lançado originalmente na Europa em 1993 [1]. Para atender às especificidades dos diferentes meios de transporte do fluxo de informação, três normas foram desenvolvidas: para satélite (DVB-S), para cabo (DVB-C) e para enlaces terrestres radio propagados (DVB-T). Este último - que é o foco do presente trabalho - foi criado em 1996, sendo que as primeiras transmissões comerciais DVB-T aconteceram na Suécia e no Reino Unido, em 1998 [1].

No Brasil, em 2006 foi adotado o sistema japonês Integrated Services Digital Broadcasting Terrestial (ISDB-T), uma evolução do DVB-T. Em 2007 foi lançada a versão brasileiro-japonesa ISDB-Tb [2].

A versatilidade da tecnologia de TV digital reflete na quantidade de parâmetros que devem ser levados em consideração, pois os mesmos interferem diretamente na robustez e qualidade do sinal a ser transmitido. Assim, além da necessidade de verificação do nível de potência na recepção, devem-se avaliar também outros fatores de igual importância, dentre eles: modulação, intervalo de guarda e código corretor de erros.

Desta maneira, pela quantidade de possibilidades de configurações que podem ser pré-estabelecidas para o enlace, fica evidente 0 grau de complexidade de operar o sistema DVB-T, em comparação ao antigo sistema de transmissão analógica. De fato, foi percebido pelos autores do presente trabalho que existe no Brasil uma significativa dificuldade, por parte de técnicos e engenheiros que trabalham nas divisões de transmissão de $T V$, de se adaptarem às exigências do padrão DVB-T. Operadores dos módulos TX/RX de micro-ondas demostram limitações no momento de configurar corretamente os parâmetros do padrão digital nestes equipamentos. Consequentemente, não se alcança o uso eficiente destes equipamentos para o estabelecimento de enlaces confiáveis nas mais variadas condições topográficas, incluindo situações de falta de visada direta.
Neste contexto, o presente artigo pretende contribuir para a melhoria dos procedimentos operacionais para a transmissão terrestre ponto a ponto de sinais de TV pelo padrão DVB com modulação COFDM (Coded Orthogonal Frequency Division Multiplex), através de um conjunto de sugestões de configurações para enlaces.Para esse fim foram executados testes práticos e simulações computacionais de micro-ondas digitais na região metropolitana de Porto Alegre/RS. Os casos avaliados são representativos da diversidade de condições topográficas e distâncias de enlaces, que podem ser encontrados nas situações típicas das transmissões comerciais.

Conforme será apresentado, a partir da análise dos resultados foi possível propor configurações adequadas dos parâmetros de transmissão do padrão DVB-T para o estabelecimento de enlaces de micro-ondas com qualidade, no sentido de facilitar as atividades de operação dos técnicos responsáveis das emissoras de TV do país.

\section{PADRÃO DVB-T}

Apesar de não fazer parte do escopo deste artigo o estudo dos aspectos teóricos do padrão DVB-T, mas sim sua aplicação prática, neste item serão abordados, de forma sucinta, os principais elementos que conformam o mesmo, para facilitar uma melhor compreensão do assunto.

No DVB foram adotadas para a codificação dos sinais de áudio e vídeo, assim como para a multiplexação, as normas MPEG-2, desenvolvidas pelo Moving Pictures Experts Group [3]. No caso do padrão DVB-T, o mesmo utiliza modulação COFDM, com o objetivo de transpor propagações multipercurso, danosas à transmissão [4]. O COFDM é um sistema multiportadora, capaz de operar em dois modos: 2K (1.705 portadoras) e $8 \mathrm{~K}$ (6.817 portadoras). A principal característica é a possibilidade de introdução, entre dois símbolos OFDM, de um intervalo de guarda programável $(1 / 4,1 / 8,1 / 16$ ou 1/32), o que garante ao sistema uma maior imunidade a interferências por multipercurso. Conforme a robustez desejada, a modulação pode ser: QPSK, 16QAM ou 64QAM e o corretor de erros FEC (Forward Error Corrector) pode ser programado para $1 / 2,2 / 3,3 / 4,5 / 6$ ou 7/8 [4].

Conforme mostrado na Figura 1, a estrutura do DVB-T pode ser descrita de forma esquemática por três macro blocos: o bloco Codificador, o 
bloco Estruturador de Quadro e o bloco Modulador OFDM.

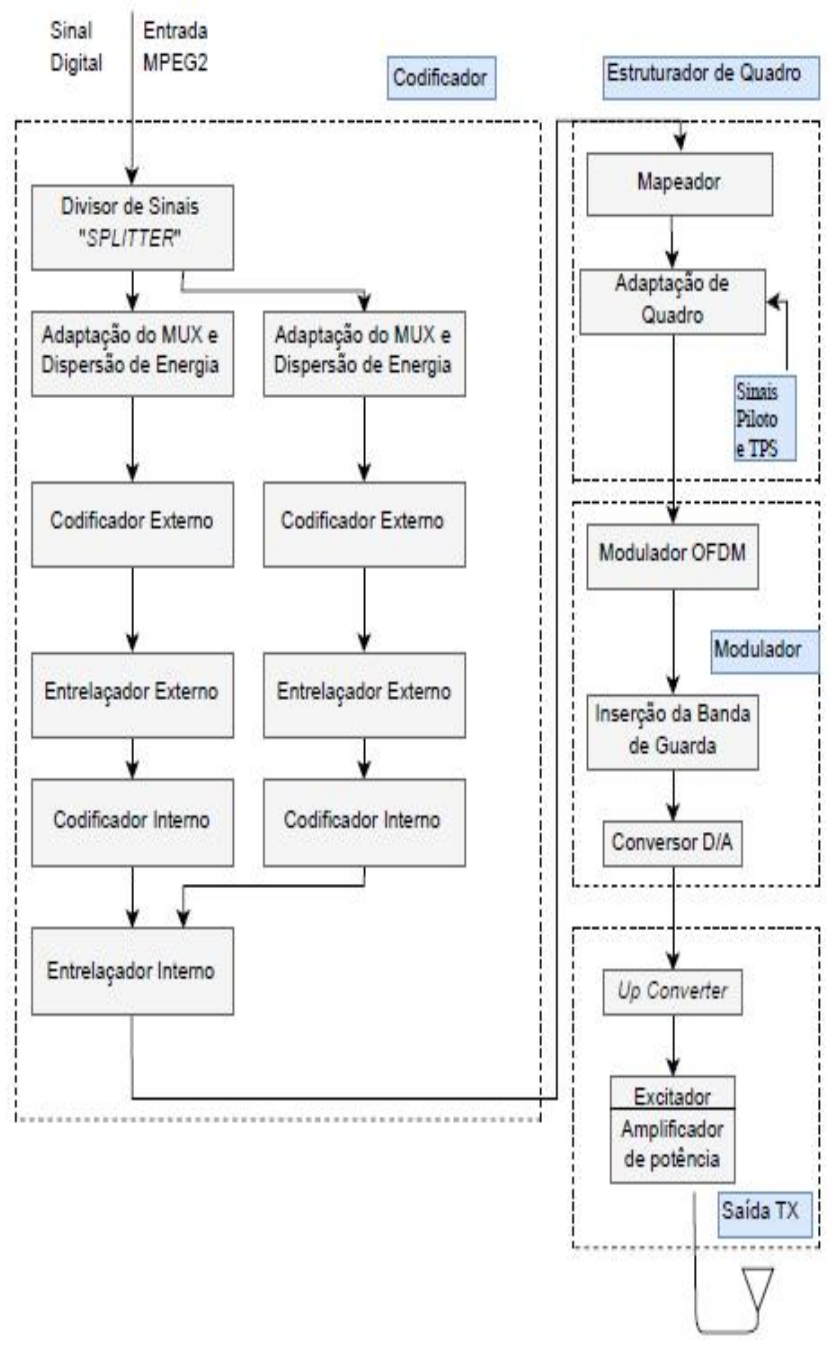

Figura 1: Diagrama da composição em macro blocos do DBV-T.

Fonte: Os autores.

Serão a seguir descritas, de forma resumida, as funções dos elementos que compõem os macroblocos supracitados.

A entrada corresponde à saída do MPEG-2, constituída por um pacote multiplexado de informações com dados, vídeo e áudio. O sinal de entrada pode ser separado em dois feixes, com conteúdos digitais diferentes, como pode ser observado no macro bloco Codificador da Figura 1. Enquanto que um feixe, por exemplo, poderá conter um sinal de TV digital Standard (SD), o outro feixe portará um sinal de outro canal de TV digital destinado ao serviço móvel. No caso de um canal único de HDTV, será utilizado apenas um feixe digital e, portanto, existirá sinal digital apenas em uma das saídas do divisor de sinais.

Os pacotes provenientes do multiplexador MPEG2, sofrem um processo de randomização no Dispersor de Energia. Na sequência, os dados são organizados e injetados no bloco do Codificador Externo (do tipo Reed Solomon). O mesmo tem como função principal permitir ao receptor detectar e corrigir erros que apareçam no sinal demodulado e regenerado. Já no Entrelaçador Externo os bytes do canal de entrada são embaralhados.

O Codificador Interno está baseado em um código-mãe, cuja taxa de código (code rate) ou FEC é de $1 / 2$. Ou seja, para cada bit de entrada tem-se dois na saída. A função do mesmo é complementar a codificação Reed Solomon, isto é, permitir ao receptor detectar e corrigir erros introduzidos por interferências e ruído presentes no meio de transmissão. A codificação convolucional usada no DVB-T permite escolher outros valores de FEC, através de um processo de puncionamento. Assim, pode-se configurar 0 Codificador Interno para trabalhar com 1/2, 2/3, $3 / 4,5 / 6$ ou $7 / 8$, variando a taxa de bits na saída do codificador, em relação à entrada. Quanto maior for a fração do FEC, menor será a diferença entre as taxas de bits codificados e de informação. Entretanto, pior será a robustez às interferências que o código confere ao sistema. Nota-se, por exemplo, que cada vez que se utiliza um nível de FEC mais robusto (menor fração), diminui-se a taxa de transmissão de informação (bits/s) mas, ao mesmo tempo, também será menor aprobabilidade de erro de bit na recepção.

O Entrelaçador Interno é constituído por três blocos funcionais distintos, a saber: demultiplexador, entrelaçador de blocos e entrelaçador de símbolos. O demultiplexador divide o feixe de entrada em dois feixes de saída para a modulação QPSK ou, em quatro feixes de saída para a modulação 16QAM. Ainda, podem ser obtidos seis feixes para a modulação 64QAM. O entrelaçador de blocos embaralha os bits contidos em blocos de 126 bits. No entrelaçador de símbolos, os sinais agrupados em $n$ bits $(2,4$ ou 6 bits) são sequencializados para formar um símbolo OFDM, em que cada uma das subportadoras assumirá um dos $2^{\text {n }}$ estados possíveis [5]. 
O Bloco Estruturador de Quadro tem como principais funções mapear o sinal de entrada em uma estrutura de quadro adequada, inserir nesta estrutura os sinais que terão a responsabilidade de enviar as configurações do receptor ou Transmission Parameter Signals (TPS), assim como também inserir as informações transportadas pelos pilotos para o sincronismo de quadro, de frequência, estimação de canal e identificação do modo de transmissão. É constituído pelos blocos Mapeador e Adaptação de Quadro.

O último processo da modulação é formado pelo Modulador OFDM. Esta técnica pode ser definida de forma simplificada como uma forma de modulação de multiportadora, em que o espaçamento da portadora é cuidadosamente selecionado de modo que cada subportadora seja ortogonal em relação às outras subportadoras. Assim, cada subcanal é modulado separadamente com um símbolo, sendo que no DVB-T é utilizada a Transformada Rápida de Fourier (FFT) [6]. Na sequência, os subcanais são multiplexados por divisão de frequência.

Durante uma transmissão, pode haver a dificuldade de separação dos subcanais individuais por FFT, devido à distorção do canal de transmissão. Uma solução simples é criar um intervalo de guarda ciclicamente prolongado, em que cada símbolo OFDM é precedido por uma extensão periódica do sinal. Quando o intervalo de guarda é maior que a resposta ao impulso do canal, ou que $o$ atraso de multipercurso, a interferência pode ser eliminada.

No padrão DVB-T, quatro tipos de intervalo de guarda (dadas como frações de um período de símbolo), estão disponíveis: $1 / 32,1 / 16,1 / 8$ e $1 / 4$ [4]. Portanto, $1 / 32$ oferece menos proteção e maior velocidade de transferência de dados. Por outro lado, o intervalo de $1 / 4$ garante a melhor proteção, mas com menor velocidade de transferência de dados.

Finalmente, após todas as operações descritas previamente para a geração do sinal digital OFDM torna-se necessário converter o mesmo para o domínio analógico, com a finalidade de poder confiná-lo em uma banda de 6,7 ou $8 \mathrm{MHz}$ [5]. Essa conversão é realizada por um Conversor D/A (digital/analógico). A partir dessa conversão, o sinal é transferido na frequência intermediaria (FI) para o Circuito de Saída TX, que gera a portadora com a frequência de operação do enlace de microondas.

\section{ESTUDO DE CASOS}

Para verificar as melhores configurações dos parâmetros de transmissão do padrão DVB-T, foram realizados testes de enlaces na região metropolitana de Porto Alegre/RS. Foram utilizados equipamentos portáteis TX/RX de micro-ondas digitais COFDM da marca NUCOMM [7], com antena de $20 \mathrm{dBi}$ de ganho, montada em um mastro em uma viatura da RBS TV, emissora filiada à Rede Globo no Rio Grande do Sul (ver Figura 2).

O local de recepção para todos os enlaces praticados foi o mesmo: a central de distribuição da RBS TV em Porto Alegre, conhecida como "RF Central", localizada no Morro da Polícia. A torre de recepção contem seis antenas, com ganho de $14,5 \mathrm{dBi}$ cada, que em conjunto garantem os $360^{\circ}$ de cobertura horizontal. Conforme ilustra a Figura 3, o sinal recebido pelas antenas segue através de cabo coaxial até a central de recepção (central de recepção RX6). Na saída da central, o sinal é encaminhado até os receptores e decodificadores de sinal (IRD) via rádio digital. No IRD foram colhidas as informações dos parâmetros dos enlaces.

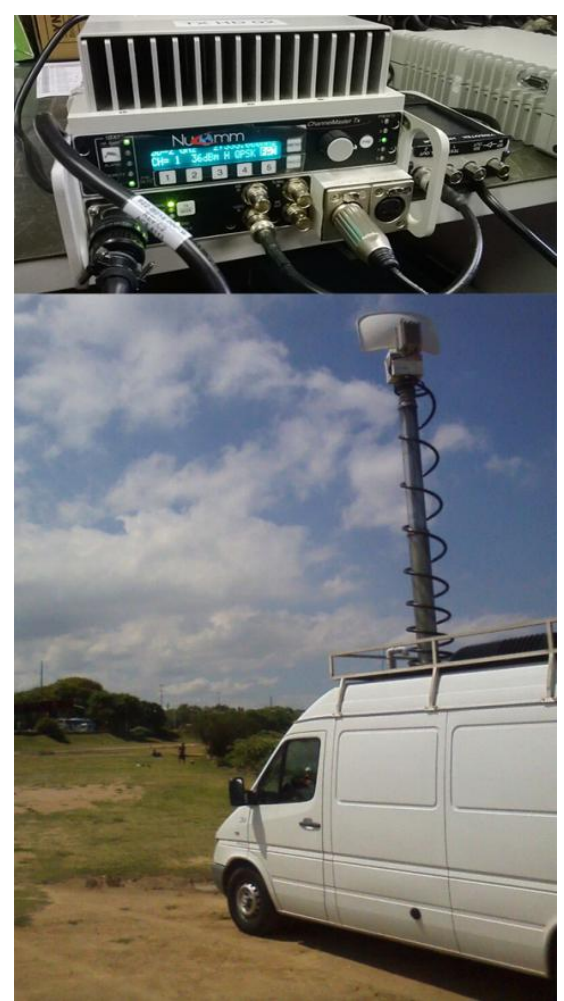

Figura 2: Equipamento transmissor de micro-ondas digital e viatura utilizada nos testes de enlaces. Fonte: Os autores. 


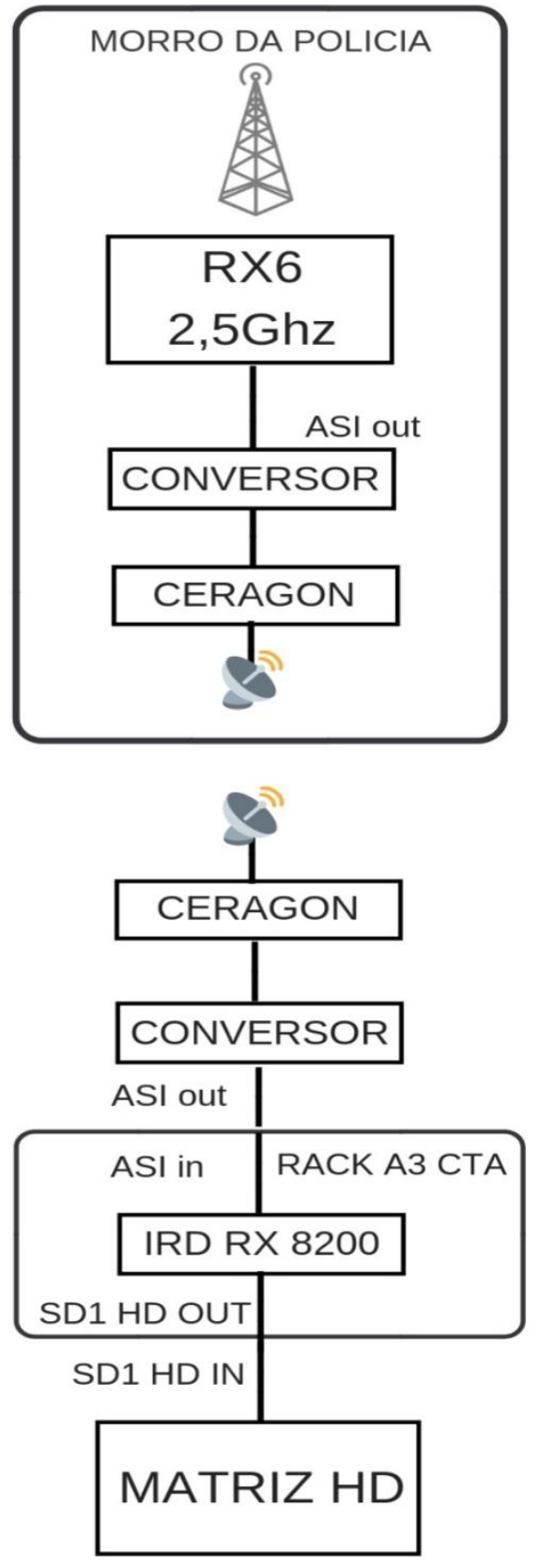

Figura 3: Diagrama da recepção dos enlaces de microondas digital.

Fonte: Os autores.

Na Tabela 1 são apresentadas as combinações possíveis dos parâmetros de transmissão DVB-T e suas respectivas taxas de bits, geradas para uma largura de banda de $8 \mathrm{MHz}$, que é a utiliza nas micro-ondas digitais COFDM no caso de enlaces terrestres [7].
Tabela 1: Taxa de dados para as combinações possíveis de parâmetros do padrão DVB-T.

\begin{tabular}{|c|c|c|c|c|c|}
\hline \multirow{3}{*}{$\begin{array}{l}\text { SISTEMA DE } \\
\text { MODULAÇÃOO }\end{array}$} & \multirow{3}{*}{ FEC } & \multicolumn{4}{|c|}{ INTERVALO DE GUARDA } \\
\hline & & $1 / 32$ & $1 / 16$ & $1 / 8$ & $1 / 4$ \\
\hline & & \multicolumn{4}{|c|}{ Taxa de dados (Mbit/s) } \\
\hline \multirow{5}{*}{ QPSK } & $1 / 2$ & 6,03 & 5,85 & 5,53 & 4,98 \\
\hline & $2 / 3$ & 8,04 & 7,81 & 7,37 & 6,63 \\
\hline & $3 / 4$ & 9,05 & 8,78 & 8,29 & 7,46 \\
\hline & $5 / 6$ & 10,05 & 9,76 & 9,21 & 8,29 \\
\hline & $7 / 8$ & 10,55 & 10,24 & 9,68 & 8,71 \\
\hline \multirow{5}{*}{ 16-QAM } & $1 / 2$ & 12,06 & 11,70 & 11,05 & 9,95 \\
\hline & $2 / 3$ & 16,08 & 15,61 & 14,74 & 13,27 \\
\hline & $3 / 4$ & 18,09 & 17,56 & 16,58 & 14,92 \\
\hline & $5 / 6$ & 20,10 & 19,51 & 18,43 & 16,58 \\
\hline & $7 / 8$ & 21,11 & 20,49 & 19,35 & 17,42 \\
\hline \multirow{5}{*}{ 64-QAM } & $1 / 2$ & 18,10 & 17,56 & 16,59 & 14,93 \\
\hline & $2 / 3$ & 24,13 & 23,42 & 22,12 & 19,91 \\
\hline & $3 / 4$ & 27,14 & 26,35 & 24,88 & 22,39 \\
\hline & $5 / 6$ & 30,16 & 29,27 & 27,65 & 24,88 \\
\hline & $7 / 8$ & 31,67 & 30,74 & 29,03 & 26,13 \\
\hline
\end{tabular}

Fonte: [7].

A potência de transmissão da portadora de micro-ondas foi de $5 \mathrm{~W}$ e a frequência de 2.335 $\mathrm{MHz}$. A altura da antena variou entre um metro e meio e dez metros em relação ao solo. Esta variação na altura não influenciou nos resultados dos testes. $\mathrm{Na}$ recepção, a antena esteve posicionada a uma altura de 60 metros da superfície do solo, montada na torre da RBS TV. O site de recepção possui um filtro instalado após a antena, para evitar desvanecimentos provocados por interferência de outros canais. Ainda, considera-se o valor de $20 \mathrm{~dB}$ como o nível mínimo de relação sinal ruído para garantir a operação adequada do receptor.

Para fins de comparação, também foram executadas simulações computacionais considerando os parâmetros dos enlaces praticados. Para isso, foram utilizados os programas PROGIRA ${ }^{\circledR}$ [8] e SIGANATEL [9].

\subsection{Casos de Enlaces com Visada Direta}

A Tabela 2 mostra as informações de três dos enlaces praticados, nomeados pelo local do ponto de transmissão. O principal objetivo destes testes foi verificar a viabilidade de enlaces com visada direta em meias e longas distâncias, aplicando uma configuração DVB-T do equipamento de micro-ondas que é bastante usual nas operações comerciais das emissoras de TV: modulação QPSK (também foi testado com 16QAM), FEC 3/4, intervalo de guarda $1 / 8$ e banda de $8 \mathrm{MHz}$. Esta DOI: $10.25286 /$ repa.v4i3.996 
configuração de parâmetros pode ser considerada como intermediária, pelo fato de fornecer níveis médios de robustez e de taxa de bits.

Tabela 2: Informações dos enlaces em visada direta $($ FEC $=3 / 4$; Int. Guarda $=1 / 8$ ).

\begin{tabular}{|c|c|c|c|}
\hline Parâmetros & \multicolumn{3}{|c|}{ Enlaces } \\
\hline Ponto TX & $\begin{array}{l}\text { Santuário } \\
\text { das Mães }\end{array}$ & $\begin{array}{c}\text { Arena de } \\
\text { Grêmio }\end{array}$ & $\begin{array}{c}\text { Hotel Vila } \\
\text { Ventura }\end{array}$ \\
\hline Ponto RX & \multicolumn{3}{|c|}{ Torre da RBS TV (Morro da Polícia/POA) } \\
\hline $\begin{array}{l}\text { Distância } \\
(\mathrm{km})\end{array}$ & 50 & 12 & 15 \\
\hline $\begin{array}{l}\text { Potência RX } \\
\text { medida } \\
(\mathrm{dBm})\end{array}$ & $-71,5$ & $-61,7$ & $-63,2$ \\
\hline $\begin{array}{l}\text { Relação sinal } \\
\text { ruído }(\mathrm{dB}) \\
\text { medida }\end{array}$ & 21,5 & 22,8 & 23,3 \\
\hline $\begin{array}{c}\text { Potência RX } \\
\text { simulada } \\
(\mathrm{dBm})\end{array}$ & $-67,5$ & $-52,1$ & $-59,4$ \\
\hline $\begin{array}{c}\text { Taxa de } \\
\text { dados para } \\
\text { QPSK (Mbps) }\end{array}$ & \multicolumn{3}{|c|}{8,29} \\
\hline $\begin{array}{l}\text { PRE Viterbi } \\
\text { (Bits errados } \\
\text { para QPSK) }\end{array}$ & 0 & 0 & 0 \\
\hline $\begin{array}{c}\text { Taxa de } \\
\text { dados para } \\
\text { 16QAM } \\
\text { (Mbps) }\end{array}$ & \multicolumn{3}{|c|}{16,6} \\
\hline $\begin{array}{l}\text { PRE Viterbi } \\
\text { (Bits errados } \\
\text { para 16QAM) }\end{array}$ & 4 & 2 & 1.857 \\
\hline $\begin{array}{c}\text { BER para } \\
\text { 16QAM }\end{array}$ & $2,41 \cdot 10^{-7}$ & $1,2 \cdot 10^{-7}$ & $1,12 \cdot 10^{-4}$ \\
\hline $\begin{array}{l}\text { POS Viterbi } \\
\text { (Bits errados } \\
\text { para 16QAM) }\end{array}$ & 0 & 0 & 54 \\
\hline
\end{tabular}

No tocante à correção dos erros na recepção, o equipamento empregado aplica na decodificação o algoritmo Viterbi [7]. Na Tabela 2 são apresentados os valores medidos de número de bits errados (PRE Viterbi Erros) e a taxa de erro de bits (BER-Bit ErrorRate), após a decodificação e antes da correção (isto é, antes da atuação do FEC). Também, mostra o número de erros após a correção (POS Viterbi Erros).

Utilizando a modulação QPSK não foram detectados erros de bit na recepção para nenhum dos enlaces praticados. Assim, a configuração padrão de FEC $3 / 4$ e intervalo de guarda de $1 / 8$ foi suficiente para garantir enlaces viáveis e com robustez adequada, sem possibilidades de falhas na recepção.
Na medida em que a modulação foi alterada para 16QAM - no intuito de dobrar a taxa de transmissão de dados - são gerados erros de bit na recepção, fato que aumenta a probabilidade de degradação de imagem e áudio recebidos. A pior situação correspondeu ao caso do enlace do Hotel Vila Ventura, com um elevado número de bits errados na recepção (1.857), implicando em uma taxa de erro de bit de $1,12 \cdot 10^{-4}$, valor ligeiramente superior ao limiar de $B E R_{\text {máx }}=10^{-4}$, que considera o sistema "quase sem erro" para as comunicações digitais terrestres [10]. Mesmo após a correção, o sinal decodificado continuou a manter uma quantidade significativa de bits errados (54).Uma solução alternativa para este caso seria aumentar a robustez modificando o FEC para 1/2, mas a taxa útil de transmissão diminuiria muito,considerando a largura de banda que está sendo utilizada. Para os outros dois enlaces praticados (Santuário das Mães e Arena do Grêmio), após a atuação do FEC na condição de modulação 16QAM todos os erros de bits puderam ser eliminados (ver última linha da Tabela 2).

Por outro lado, conforme pode ser observado na Tabela 2, houve uma boa aproximação entre os valores de potência de recepção medidos e simulados. Para todos os casos, os níveis de recepção simulados foram maiores que os medidos, sendo o enlace da Arena do Grêmio o que apresentou maior divergência. Entre as possíveis causas que levaram à diferença entre os valores medidos e calculados podem ser citadas: a) desalinhamento entre a antena transmissora e a receptora; b) possíveis perdas em conectores e cabos que não foram consideradas no cálculo; c) possíveis sinais interferentes e d) obstruções não consideradas na simulação, devidas à presença de árvores e prédios nos locais da transmissão. A Figura 4 apresenta os gráficos computacionais do percurso dos enlaces e do perfil dos terrenos ao longo dos trajetos. Estas imagens foram obtidas dassimulações executadas com 0 software SIGANATEL. Fica evidente a visada direta para os três casos avaliados. 


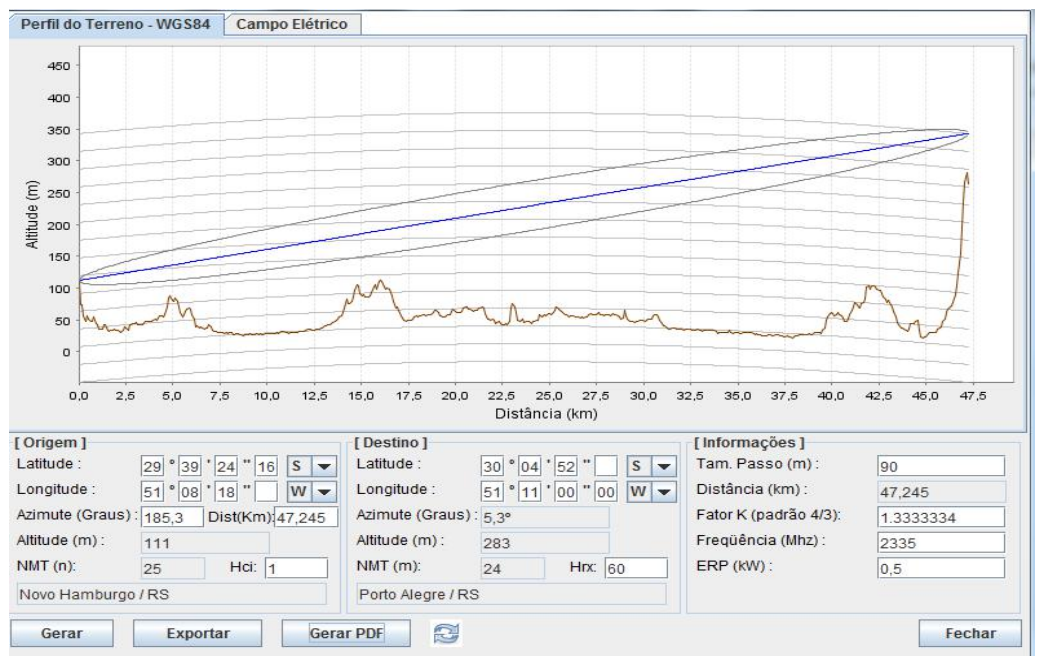

(a)

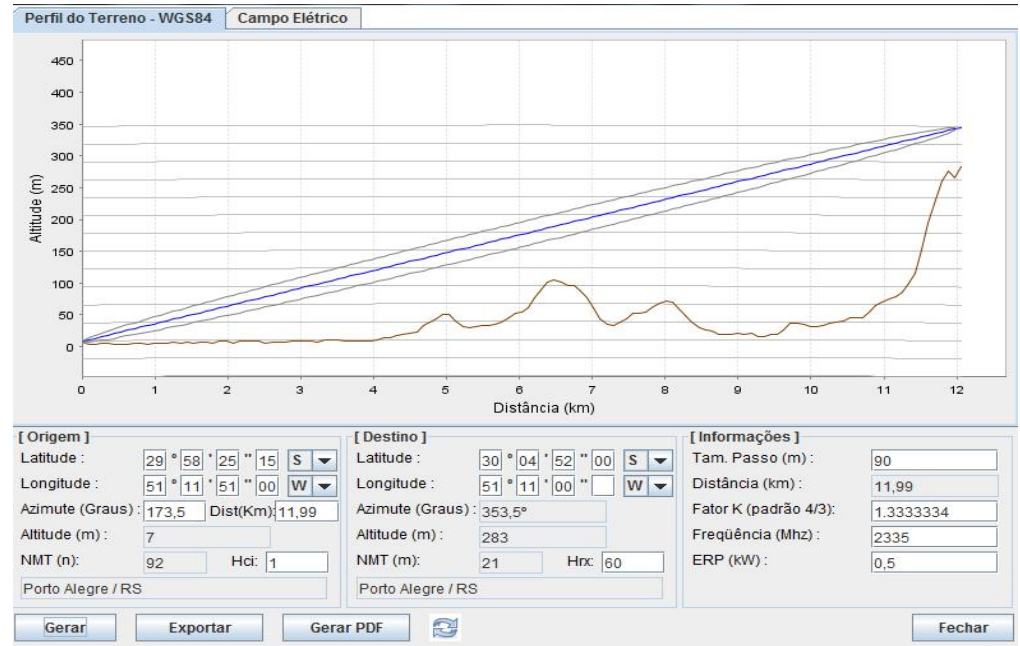

(b)

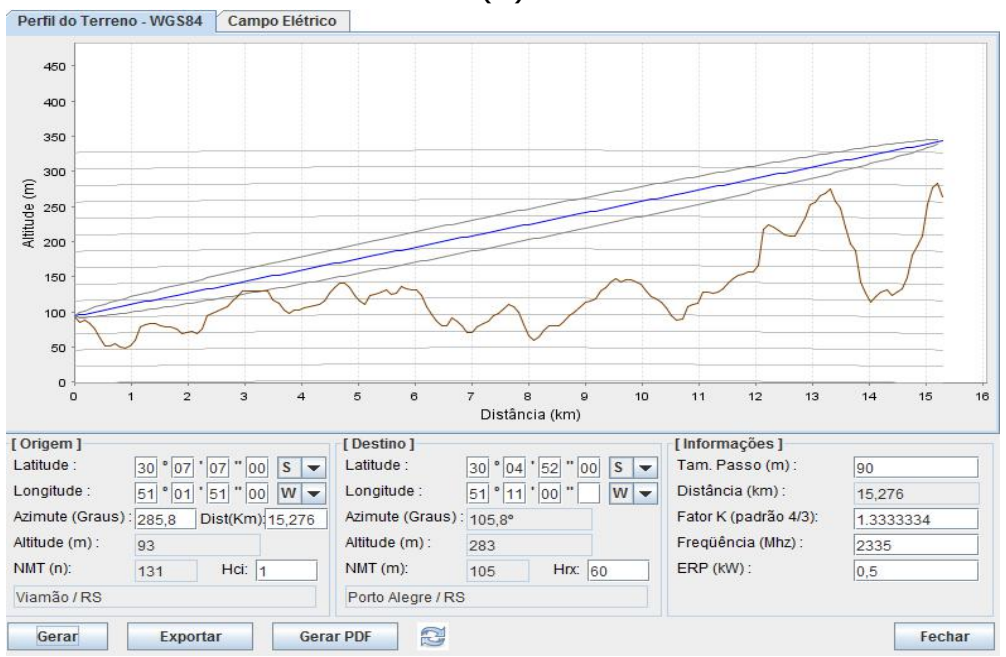

(c)

Figura 4: Simulação do perfil de elevação dos enlaces. a) Santuário das Mães; b) Arena do Grêmio; c) Hotel Vila Ventura. 


\subsection{Caso de Enlace com Alteração dos Parâmetros DVB-T}

Este teste foi realizado na região metropolitana de Porto Alegre, tendo como ponto de transmissão um local no bairro Harmonia, na cidade de Canoas, com uma distância de aproximadamente $20 \mathrm{~km}$ em visada direta até a torre da RBS TV. Para todas as situações, a antena transmissora ficou a 10 metros do solo. $\mathrm{O}$ objetivo deste estudo de caso foi alterar a configuração dos parâmetros FEC e intervalo de guarda, no intuito de verificar o impacto das modificações na qualidade da recepção do sinal digital. A modulação praticada foi a QPSK, pois atendendo ao elevado comprimento do enlace, as modulações 16QAM e 64QAM gerariam muitos erros de bits na recepção, fragilizando a robustez e até inviabilizando a conexão. Na Tabela 3 são mostrados os resultados para as configurações praticadas.

Tabela 3: Informações dos testes de enlaces variando os parâmetros de transmissão.

\begin{tabular}{|c|c|c|c|}
\hline Ponto TX & \multicolumn{3}{|c|}{ Harmonia/Canoas } \\
\hline Ponto RX & \multicolumn{3}{|c|}{ Torre da RBS TV (Morro da Polícia/POA) } \\
\hline $\begin{array}{c}\text { Distância } \\
(\mathbf{k m})\end{array}$ & \multicolumn{3}{|c|}{20} \\
\hline Modulação & \multicolumn{3}{|c|}{ QPSK } \\
\hline Teste & 1 & 2 & 3 \\
\hline FEC & $3 / 4$ & $7 / 8$ & $2 / 3$ \\
\hline $\begin{array}{c}\text { Intervalo de } \\
\text { guarda }\end{array}$ & $1 / 16$ & $1 / 32$ & $1 / 4$ \\
\hline $\begin{array}{c}\text { Taxa de dados } \\
\text { (Mbps) }\end{array}$ & 8,78 & 10,55 & 6,63 \\
\hline $\begin{array}{l}\text { Potência RX } \\
(\mathrm{dBm})\end{array}$ & $-85,3$ & $-85,1$ & $-85,4$ \\
\hline $\begin{array}{l}\text { Relação sinal } \\
\text { ruído (dB) }\end{array}$ & 17,9 & 19 & 20,5 \\
\hline $\begin{array}{c}\text { PRE Viterbi } \\
\text { (Bits errados) }\end{array}$ & 10 & 27 & 9 \\
\hline BER & $1,14 \cdot 10^{-6}$ & $2,56 \cdot 10^{-6}$ & $1,36 \cdot 10^{-6}$ \\
\hline $\begin{array}{c}\text { POS Viterbi } \\
\text { (Bitserrados) }\end{array}$ & 0 & 2 & 0 \\
\hline
\end{tabular}

$\mathrm{Na}$ primeira configuração, optou-se por selecionar a modulação QPSK, FEC 3/4 e intervalo de guarda de 1/16, conforme apresentado na Tabela 3. Estes valores são considerados intermediários em relação ao quesito robustez. A taxa de transmissão de dados para esta combinação foi $8,78 \mathrm{Mbps}$. O nível de potência do sinal recebido foi de $-85,3 \mathrm{dBm}$. Os erros de bits gerados na recepçãoforam corrigidos completamente pelo corretor de erros.

No segundo caso, foi aplicado um FEC 7/8 e intervalo de guarda de $1 / 32$, com uma taxa gerada de 10,55 Mbps. O nível de sinal permaneceu semelhante ao caso anterior. Apesar da taxa de dados obtida ser superior, devido à menor robustez da configuração em relação ao teste anterior, acabou-se gerando uma quantidade maior de erros de bit que não foram totalmente corrigidos. Desta forma, a qualidade de recepção do sinal foi prejudicada.

Para o terceiro caso, com alteração dos parâmetros do FEC para 2/3 e intervalo de guarda para 1/4, a taxa gerada foi de 6,63 Mbps. Apesar da taxa de dados ser a menor dentre os casos avaliados, foi conseguida a configuração mais robusta de todas. Assim, foram gerados poucos erros de bit os quais foram corrigidos na sua totalidade.

\section{ANÁLISE SOBRE AS CONFIGURAÇÕES DOS PARÂMETROS DE TRANSMISSÃO DVB-T}

Conforme foi tratado ao logo do presente trabalho, a configuração dos parâmetros DVB-T (Intervalo de guarda, FEC e tipo de modulação OFDM), influencia diretamente na taxa útil de bits gerada na saída do transmissor que, por sua vez, tem impacto na robustez e qualidade do sinal. Ainda, a escolha destes parâmetros também interfere na capacidade de correção dos erros gerados durante a transmissão.

\subsection{Considerações em Relação ao Intervalo de Guarda}

Nas transmissões com micro-ondas digitais em locais com obstruções de prédios, morros, veículos ou qualquer outro objeto que possa causar reflexão do sinal, deve-se optar por um valor de intervalo de guarda elevado (ex. 1/4 ou $1 / 8)$. Desta maneira, é possível aproveitar as reflexões causadas pelos obstáculos de forma a obter interferência construtiva na recepção, pelo fato dos sinais refletidos estarem dentro do mesmo período de leitura do sinal original. No entanto, essa escolha implica em taxas de dados menores.

Por outro lado, em situações em que o enlace aconteça em um ambiente livre de obstáculos, pode-se configurar um período de intervalo de guarda menor (ex. 1/16 ou 1/32), visto que não haverá reflexões relevantes pelo caminho. Neste 
caso, a taxa útil de dados gerada na saída do receptor será incrementada, aproveitando melhor a banda de frequência disponível.

\subsection{Considerações em Relação ao Corretor de Erros}

É de fundamental importância realizar a configuração do FEC levando em consideração a quantidade de erros presentes no receptor de micro-ondas. $\mathrm{Na}$ situação de enlaces que contenham erros na recepção, com a consequente degradação da qualidade na imagem ou no áudio do sinal, deve-se proceder à inserção de bits de redundância para realizar a correção dos mesmos. Deste modo, a viabilidade de uma recepção adequada será possível com o aumento da capacidade de correção dos erros de bits gerados no enlace.

Enlaces de longas distâncias e com a presença de obstáculos que causem reflexões no sinal, apresentam maior probabilidade de aumento na quantidade de erros de bits na recepção. No caso, deverá ser aplicado um FEC de $2 / 3$ (um bit de correção para cada dois bits úteis) ou de $1 / 2$ (um bit de correção para cada bit útil). Esses valores de FEC irão garantir mais bits de correção em relação aos bits úteis. No entanto, valores altos de FEC também resultam na diminuição da taxa útil de bits. Assim, em uma situação em que não existam erros na recepção para serem corrigidos, como é tipicamente o caso de enlaces de curta distância e com poucas reflexões, aconselha-se reduzir O FEC para $5 / 6$ ou $7 / 8$. Desta forma, a banda será melhor aproveitada, aumentando a taxa de dados e consequentemente a qualidade da recepção.

\subsection{Considerações em Relação à Modulação}

O parâmetro que exerce maior influência no desempenho do sinal a ser transmitido é a modulação. Os equipamentos de micro-ondas digital possuem a opção de três tipos de modulação: QPSK, 16QAM e 64QAM, onde QPSK é a mais robusta (menores erros de bits) e 64QAM permite a maior qualidade (maior taxa de dados) de transmissão. Os outros parâmetros (FEC e intervalo de guarda), deverão ser configurados após a definição do tipo de modulação.
A fim de comparação, o sistema mais robusto possível utilizando modulação QPSK, com FEC $1 / 2$ e intervalo de guarda $1 / 4$ gera uma taxa de bits de 4,98 Mbps. No outro extremo, para um sistema operando com modulação 64QAM, FEC $7 / 8$ e intervalo de guarda $1 / 32$ a taxa de bits atinge 31,67 Mbps. É importante lembrar que para todos os casos a banda permanece fixa em 8 $\mathrm{MHz}$.

Em um enlace no qual é exigida a máxima qualidade possível do sinal, como é o caso das transmissões em alta definição (HD), primeiramente se configura a modulação para 64QAM. Se forem observadas falhas na recepção, deve-se mudar para $16 Q A M$, pois a mesma irá permitir mais robustez ao enlace. Em situações de transmissões de longa distância ou que não demandem transmissão em HD, aconselha-se configurar o equipamento com parâmetros que garantem maior robustez ao sinal, optando primeiramente pela modulação QPSK. Desta maneira, as chances de existirem erros na recepção serão menores, oferecendo maior confiabilidade.

\section{PROPOSTAS DE CONFIGURAÇÕES DOS PARÂMETROS EM ENLACES DVB-T}

A partir da análise dos resultados obtidos nos casos de enlaces praticados, assim como do conhecimento teórico sobre o padrão DVB-T, na Tabela 4 é apresentado um conjunto de sugestões para configurar os parâmetros de transmissão nos equipamentos de micro-ondas digital, que garantem uma transmissão confiável e de qualidade adequada, atendendo ao tipo de topografia e distância do enlace. 
Tabela 4: Propostas de configurações dos parâmetros de transmissão em enlaces DVB-T.

\begin{tabular}{|c|c|c|c|}
\hline \multirow{2}{*}{$\begin{array}{c}\text { Condições do } \\
\text { enlace } \\
\text { (distância e } \\
\text { topografia) }\end{array}$} & \multicolumn{3}{|c|}{ PARÂMETROS E TRANSMISSÃO } \\
\hline & Modulação & FEC & $\begin{array}{l}\text { Intervalo } \\
\text { de guarda }\end{array}$ \\
\hline $\begin{array}{c}\text { Grande } \\
\text { distância, sem } \\
\text { obstáculos }\end{array}$ & $\begin{array}{l}\text { QPSK ou } \\
\text { 16QAM }\end{array}$ & $3 / 4$ & $1 / 16$ \\
\hline $\begin{array}{c}\text { Grande } \\
\text { distância, alguns } \\
\text { obstáculos }\end{array}$ & QPSK & $2 / 3$ & $1 / 8$ \\
\hline $\begin{array}{c}\text { Grande } \\
\text { distância, muitos } \\
\text { obstáculos }\end{array}$ & QPSK & $1 / 2$ & $1 / 4$ \\
\hline $\begin{array}{c}\text { Pequena } \\
\text { distância, sem } \\
\text { obstáculos }\end{array}$ & $\begin{array}{c}16 \text { QAM ou } \\
\text { 64QAM }\end{array}$ & $7 / 8$ & $1 / 32$ \\
\hline $\begin{array}{c}\text { Pequena } \\
\text { distância, alguns } \\
\text { obstáculos }\end{array}$ & 16 QAM & $5 / 6$ & $1 / 8$ \\
\hline $\begin{array}{c}\text { Pequena } \\
\text { distância, muitos } \\
\text { obstáculos }\end{array}$ & $\begin{array}{l}\text { QPSK ou } 16 \\
\text { QAM }\end{array}$ & $3 / 4$ & $1 / 4$ \\
\hline
\end{tabular}

Na Tabela 4, se considera que um enlace é pequeno para distâncias de até $10 \mathrm{~km}$, já os grandes são aqueles acima de $30 \mathrm{~km}$.

\section{CONCLUSÕES}

Ao longo do desenvolvimento da pesquisa verificou-se a grande influência que as configurações dos parâmetros de transmissão DVB-T exercem no desempenho dos enlaces de micro-ondas digitais. Um importante fato a ser observado é a relação de compensação entre a robustez e a qualidade do sinal durante a transmissão, pois estas características são inversamente proporcionais. Portanto, constatouse que não existe uma "configuração ideal" preestabelecida de parâmetros que possa ser aplicada, devendo sempre ser avaliada a robustez necessária para viabilizar o enlace e a qualidade mínima exigida na recepção, dependendo do objetivo da transmissão.

Assim, no intuito de contornar essa situação, a principal contribuição do trabalho foi apresentar algumas sugestões de configurações dos parâmetros DVB-T, conforme listadas na Tabela 4. Por exemplo, no caso de um enlace de curta distância sem obstruções, propõe-se a modulação 16QAM, com FEC $7 / 8$ e intervalo de guarda $1 / 32$, garantindo uma taxa de 21,11 Mbps. Por outro lado, na condição extrema de um enlace de longa distância com muitos obstáculos, é sugerida a modulação QPSK, com FEC $1 / 2$ e intervalo de guarda 1/4. Neste último caso, a taxa máxima de bits fica limitada a 4,98 Mbps.

Desta forma, acredita-se que a incorporação destas configurações nos procedimentos operacionais de transmissão de enlaces terrestres de TV digital, poderá facilitar e agilizar as ações das equipes técnicas responsáveis nas emissoras.

\section{REFERÊNCIAS}

[1] HISTORY OF DVB. In: DVB Project. [s. I.], c2019. Disponível em:

http://www.dvb.org/about/history. Acesso em: 12 mar. 2018.

[2] TOME, T. et al. Abordagem Sistêmica no Sistema Brasileiro de Televisão Digital (SBTVD), 2007. Disponível em: http://www.researchgate.net/publication/. Acesso em: 08 de out. 2018.

[3] THE MOVING PICTURE EXPERTS GROUP. MPEG-2 Standars. In: The Moving Picture Experts Group. Disponível em: http://mpeg.chiariglione.org/standards. Acesso em: 20 mar. 2018.

[4] YAMADA, F. et al. Avaliação dos Sistemas de TV Digital Terrestres. New York: Springer-Verlag, 1985.

[5] Padrões de TV Digital. Revista Mackenzie de Engenharia e Computação, Ano 5, n. 5, p. 13-96.

[6] WILLIAN, Y. Z.; YIYAN, W.COFDM: An Overview. IEEE Transactions on Broadcasting. v. 41, n. 1, p. 1-8, mar. 1995.

[7] NUCOMM. Nucomm User Manual Channel Master TX7. Nucomm Publication: M01-0029$00 \mathrm{~A}$, rev 1.05.

[8] PROGIRA. Versão 5.1. Disponível em: http://www.progira.com. Acesso em: 16 mai. 2018.

[9] SIGANATEL. Sistemas de Informações Geográficas. Disponível em: http://sistemas.anatel.gov.br/siganatel Acesso em: 16 mai. 2018

[10] ARANHA, F. G.; ROCHA, C. A. Análise Comparativa da Segunda Geração do DVBT2 x DVB-T. In: SEMINÁRIO DE REDES E SISTEMAS DE TELECOMUNICAÇÕES, 5., set. 2016, Santa Rita do Sapucaí. Anais [...] Santa Rita do Sapucaí: Inatel, 2016 